\title{
FEATURES OF ENDOMETRIAL RESTRUCTURING IN HIV INFECTION
}

\author{
Lytvynenko M. \\ Odessa National Medical University, Odessa, Ukraine \\ https://doi.org/10.35339/ic.7.4.200-204
}

\begin{abstract}
The purpose of our study was to evaluate the features of endometrial restructuring when infected with the human immunodeficiency virus. Materials and methods: The study involved sectional material taken from 60 women of reproductive age from 20 to 40 years. Group 1 ( 30 women) consisted of women who were diagnosed with HIV infection. The control group comprised women (30) without concomitant HIV infection. Results. An average diameter of the endometrial glands (proliferative type) was $8 \%$ smaller in HIV infection than in the comparison group. The minimum diameter of the endometrial glands (proliferative type) decreased by $1.73 \%$, the maximum was $5.24 \%$ less in the HIV-infected group than in the comparison group. The wall thickness was reduced by $0.5 \%$ in HIV infection. The relative volume of the epithelium decreased by $2.4 \%$ (proliferative type). There were also significant changes in the structure of the glands and endometrium in secretory phase, as in the proliferative type. Thus, the average diameter of the glands decreased by $5 \%$, the minimum volume of the glands by $5.01 \%$, the maximum by $11.2 \%$, the wall thickness by $1.5 \%$, the relative volume of the epithelium by $9.5 \%$, less in the group HIV-infected than in the comparison group. The thickness of the epithelium increased by $4.5 \%$ in the HIV-infected group compared with the comparison group. Conclusion. The study evaluated features of endometrial restructuring in the presence of concomitant HIV infection in women.
\end{abstract}

Keywords: uterus, endometrium, HIV, glands.

\section{Introduction}

Many different studies have investigated the immunological and hormonal aspects of hyperplastic diseases of the uterus (HDU) [1-3]. Many authors have shown a violation of the supervisory functions of the immune system, which regulate the processes of cell proliferation [4-7]. These changes can be both hereditary and acquired during the expression or mutations of the corresponding genes during life [8]. The results of other studies have suggested that there is a genetic predisposition to the development of HDU, and genetic determinants are the main risk factors triggering pathogenic mechanisms of proliferative processes in the uterus $[9,10]$.

HIV (AIDS) today occupies a leading position among the causes of death of women of reproductive age all over the world. The

Corresponding Author:

Marianna V. Lytvynenko, MD, PhD,

associate professor of the Department

of Pathological anatomy with section course,

Odessa National Medical University, Odessa, Ukraine.

E-mail: lytvynenko_marianna@ukr.net disproportionate impact of HIV on young women may be due not only to social inequality, but also to biological patterns of heterosexual transmission of the virus [11-13]. HIV infection is a disease that affects all organs and systems of a patient. Approximately 60-90\% of HIV transmission occurs through sexual contact.

Globally, women make up more than half of the population living with HIV. The majority of women become infected during sexual intercourse, when the mucous membrane is most vulnerable to HIV infection $[14,15]$. It has a special effect on the human reproductive system. Being an entrance gate, this pathological condition starts a cascade of pathological reactions, causing various changes in all organs of the reproductive system.

The first line of defense against HIV infection in the female genital tract is the mucous membrane of the epithelial barrier [14]. Consequently, the expected maximum pronounced changes can occur precisely in the endometrium.

2. Purpose, subjects and methods:

2.1. The purpose of our study was to evaluate the features of endometrial restructuring when infected with the human immunodeficiency virus. 


\subsection{Subjects \& Methods}

The study involved the sectional material taken from 60 women of reproductive age from 20 to 40 years. All the subjects were divided into two groups. Group 1 (30 women) consisted of women who were diagnosed with HIV infection.

The control group comprised women (30) who died from diseases not associated with reproductive disorders without concomitant HIV infection (deaths as a result of traffic and other accidents).

The material was fixed in $10 \%$ neutral buffered formalin, after which the selected samples were embedded in paraffin. At the next stage, sections with a thickness of $5 r 10^{-6} \mathrm{~m}$ were made from the prepared paraffin blocks. Subsequently, staining with hematoxylin and eosin was performed. Microscopic examination was carried out on an Olympus BX41 microscope, followed by morphometric examination using the Olympus DP-soft 3.12 software.

The following indicators were determined: average diameter of the endometrial glands (proliferative type), minimum diameter of the endometrial glands (proliferative type), maximum diameter of the endometrial glands (proliferative type), wall thickness (proliferative type), relative volume of the epithelium (proliferative type), average diameter of the glands (secretory type), minimum diameter of the glands (secretory type), maximum diameter of the glands (secretory type), relative volume of the epithelium (secretory type), thickness of the epithelium.

Statistical processing was performed using the methods of variation statistics. Correspondence of the distribution to normal was determined by Shapiro-Wilk's test, which showed that the samples were close to the normal distribution. Statistical indicators are presented in the format $\mathrm{M} \pm \sigma$, where $\mathrm{M}$ is the arithmetic mean, $\sigma$ is the standard deviation. Student's t-test was used. Correlation analysis was carried out using Spearman's rank correlation coefficient. The statistical difference between the studied parameters was considered significant at $p$ less than 0.05 .

The procedure was done strictly in compliance with the Helsinki Declaration after approval from the Regional Ethical Review Board at Odessa National Medical University, protocol No. 3 dated $17^{\text {th }}$ October 2011.

\section{Conflict of interests}

The authors of the article declare no conflict of interest.

\section{Results \& discussion}

Results of performed morphometric study are shown in the table.

Thus, the study showed that the average diameter of the endometrial glands (proliferative type) was $8 \%$ smaller in HIV infection than in the comparison group. The minimum diameter of the endometrial glands (proliferative type) decreased by $1.73 \%$, the maximum was $5.24 \%$ less in the HIV-infected group than in the comparison group. The wall thickness was reduced by only $0.5 \%$ in HIV infection.

The relative volume of the epithelium decreased by $2.4 \%$ (proliferative type) in the HIV-infected group compared with the comparison group.

\section{Indicators of the structure of endometrium in HIV infection and in the comparison group}

\begin{tabular}{|c|c|c|}
\hline Parameter under study & Comparison group & HIV-infected women \\
\hline $\begin{array}{l}\text { The average diameter of the endometrial } \\
\text { glands (proliferative type) } \times 10^{-6} \mathrm{~m}\end{array}$ & $51.71 \pm 2.90$ & $47.62 \pm 2.29$ \\
\hline $\begin{array}{l}\text { The minimum diameter of the endometrial } \\
\text { glands (proliferative type), } \times 10^{-6} \mathrm{~m}\end{array}$ & $32.47 \pm 1.83$ & $31.88 \pm 1.92$ \\
\hline $\begin{array}{l}\text { The maximum diameter of the endometrial } \\
\text { glands (proliferative type), } \times 10^{-6} \mathrm{~m}\end{array}$ & $72.14 \pm 2.21$ & $68.36 \pm 3.15$ \\
\hline Wall thickness (proliferative type),$\times 10^{-6} \mathrm{~m}$ & $15.18 \pm 1.60$ & $15.10 \pm 1.04$ \\
\hline $\begin{array}{l}\text { The relative volume of the epithelium } \\
\text { (proliferative type), \% }\end{array}$ & $54.43 \pm 1.79$ & $53.12 \pm 2.41$ \\
\hline $\begin{array}{l}\text { The average diameter of the glands (secretory } \\
\text { type), } \times 10^{-6} \mathrm{~m}\end{array}$ & $101.55 \pm 3.12$ & $96.34 \pm 4.26$ \\
\hline $\begin{array}{l}\text { Minimum diameter of glands (secretory type), } \\
\times 10^{-6} \mathrm{~m}\end{array}$ & $33.86 \pm 1.17$ & $32.14 \pm 1.67$ \\
\hline $\begin{array}{l}\text { Maximum diameter of glands (secretory type), } \\
\times 10^{-6} \mathrm{~m}\end{array}$ & $127.98 \pm 2.10$ & $113.64 \pm 3.51$ \\
\hline Wall thickness (secretory type),$\times 10^{-6} \mathrm{~m}$ & $13.02 \pm 1.36$ & $12.82 \pm 1.26$ \\
\hline $\begin{array}{l}\text { The relative volume of the epithelium } \\
\text { (secretory type), \% }\end{array}$ & $61.24 \pm 1.11$ & $55.43 \pm 1.70$ \\
\hline Epithelial thickness, $\times 10^{-6} \mathrm{~m}$ & $49.14 \pm 1.44$ & $51.33 \pm 1.23$ \\
\hline
\end{tabular}


At the next stage the indicated indicators (secretory type) were investigated.

There were also significant changes in the structure of the glands and endometrium, as in the proliferative type. Thus, the average diameter of the glands decreased by $5 \%$, the minimum volume of the glands by $5.01 \%$, the maximum by $11.2 \%$, the wall thickness by $1.5 \%$, the relative volume of the epithelium by $9.5 \%$, less in the group HIV-infected than in the comparison group.

The thickness of the epithelium increased by $4.5 \%$ in the HIV-infected group compared with the comparison group. Our study identified the changes in the endometrium due to the presence of concomitant HIV infection in women. Based on the data obtained, it can be assumed that concomitant HIV infection stimulates the development of hyperplastic changes in the endometrium.

There are reports in the literature on the "inflammatory" origin of HDU [16-18]. It is known that in the presence of long-term $[19,20]$, often exacerbated inflammatory processes of the genital organs, the risk of endometrial cancer increases 20 times, and against a background of HDU - 15 times [21-22]. Long-term persistent infection of the genital organs leads to a change in the receptors of estradiol and progesterone in the tissue of the endo- and myometrium.

Nevertheless, it is probably fair to consider the fact that in the development of hyperplastic processes, the main role is traditionally assigned to an increase in the concentration of estrogens [23].

Changes of the HER (human epidermal growth factor receptor) expression should be considered the most frequent problem of the state of the endometrium and as a consequence of the actual problem in the female population and oncological alertness due to its high prevalence [24, 25]. Today HDU is officially recognized to be one of the most important and potentially health-damaging medical problems that challenge doctors around the world. The steady increase in the number of patients with HDU, unclear etiology, variable clinical manifestations and a high relapse rate and risk of malignancy, as well as low treatment efficacy have led to a significant increase in scientific interest in this problem in recent years [26].

In Ukraine, the HIV-infected population is growing every year with the overwhelming majority $(77.6 \%$ of people of young, reproductive and working age, i.e.15-49 years), the number of HIV-infected pregnant women is increasing [27], which is explained by the high proportion of women of reproductive age among the patients with HIV infection.
Currently, HDU is defined as a pathological process affecting the epithelial and stromal components of the endometrium and manifested by an increase in the total number of glands, as well as various changes in the phenotypic characteristics of cells [28]. Endometrioid, intraepithelial neoplasia is currently considered as a variant of atypical hyperplasia, a feature of which is the formation of foci more than $2 \mathrm{~mm}$ in diameter with a predominance of the parenchyma over the stroma, with pronounced atypia of the crowded gland cells and with loss of PTEN (phosphatase and tensin homolog) expression [29].

Currently, interesting and at the same time contradictory statistical data are given in relation to the combined pathological processes of the endo- and myometrium, which, to some extent, can be explained by a fairly frequent asymptomatic course [30]. HDU occupies 15-40\% in the structure of all gynecological diseases, and up to $80 \%$, when combined with adenomyosis. Contradictory data in the literature are also given in relation to the combination of HDU and uterine leiomyoma, the frequency of which ranges from 13 to $80 \%$. In the asymptomatic course of uterine leiomyoma in postmenopausal women, every sixth patient has HDU, at the same time, when uterine bleeding appears, concomitant development of HDU is determined in every second patient [30].

It should be noted that the least reliably $(p<0.05)$ variable indicator is the thickness of the endometrial wall (proliferative type), which significantly is decreased by only $8 \mathrm{~mm}$ on average in the presence of HIV infection.

The most pronounced significant changes affected the glands, especially the secretory type. Thus, at the same time the maximum volume of the glands changed at $14 \times 106 \mathrm{~m}$. Subsequently, these findings can be confirmed by other additional studies.

Consequently, our study gives grounds to assume the possible development of hyperplastic processes in the endometrium in HIV-infected patients, which cannot but affect the peculiarities of the presentation, diagnosis and treatment of inflammatory and non-inflammatory processes of the reproductive system.

\section{Conclusions}

The study evaluated the features of endometrial restructuring in the presence of concomitant HIV infection in women. These changes are manifested by hyperplastic changes in the mucous membrane. The most pronounced changes were revealed in the endometrial glands (secretory type). 


\section{References}

1. Popova, L., Vasylyeva, L., Tkachenko, A., Polikarpova, H., Kokbas, U., Tuli, A, Kayrin, L., \& Nakonechna, A. (2019) Menstrual cycle-related changes in blood serum testosterone and estradiol levels and their ratio stability in young healthy females. Inter colleges, 6(3), 155-161.

2. Lytvynenko, M., Bocharova, T., Zhelezniakova, N., Narbutova, T., \& Gargin, V. (2017). Cervical transformation in alcohol abuse patients. Georgian medical news, (271), 12-17.

3. Shepherd, L., Borges, A., Ledergerber, B., Domingo, P., Castagna, A., Rockstroh, J., Knysz, B., Tomazic, J., Karpov, I., Kirk, O., Lundgren, J., Mocroft, A., \& EuroSIDA in EuroCOORD (2016). Infection-related and -unrelated malignancies, HIV and the aging population. HIV medicine, 17(8), 590600. https://doi.org/10.1111/hiv.12359

4. Hyriavenko, N., Lyndin, M., Sikora, K., Piddubnyi, A., Karpenko, L., Kravtsova, O., Hyriavenko, D., Diachenko, O., Sikora, V., \& Romaniuk, A. (2019). Serous Adenocarcinoma of Fallopian Tubes: Histological and Immunohistochemical Aspects. Journal of pathology and translational medicine, 53(4), 236-243. https://doi.org/10.4132/jptm.2019.03.21

5. Pelchen-Matthews, A., Ryom, L., Borges, ?. H., Edwards, S., Duvivier, C., Stephan, C., Sambatakou, H., Maciejewska, K., Portu, J. J., Weber, J., Degen, O., Calmy, A., Reikvam, D. H., Jevtovic, D., Wiese, L., Smidt, J., Smiatacz, T., Hassoun, G., Kuznetsova, A., Clotet, B., ... EuroSIDA study (2018). Aging and the evolution of comorbidities among HIV-positive individuals in a European cohort. AIDS (London, England), 32(16), 2405-2416. https://doi.org/10.1097/QAD.0000000000001967

6. Gargin, V., Radutny, R., Titova, G., Bibik, D., Kirichenko, A., \& Bazhenov, O. (2020). Application of the computer vision system for evaluation of pathomorphological images. Paper presented at the 2020 IEEE $40^{\text {th }}$ International Conference on Electronics and Nanotechnology, ELNANO 2020 - Proceedings, 469-473. doi:10.1109/ELNANO50318.2020.9088898

7. Wahlstrom, J. T., \& Dobs, A. S. (2000). Acute and long-term effects of AIDS and injection drug use on gonadal function. Journal of acquired immune deficiency syndromes (1999), 25 Suppl 1, S27S36. https://doi.org/10.1097/00042560-200010001-00005

8. Bull, L., Tittle, V., Rashid, T., \& Nwokolo, N. (2018). HIV and the menopause: A review. Post reproductive health, 24(1), 19-25. https://doi.org/10.1177/2053369117748794

9. Lytvynenko, M., Shkolnikov, V., Bocharova, T., Sychova, L., \& Gargin, V. (2017). Peculiarities of proliferative activity of cervical squamous cancer in hiv infection. Georgian medical news, (270), 10-15.

10. Zoufaly, A., Cozzi-Lepri, A., Reekie, J., Kirk, O., Lundgren, J., Reiss, P., Jevtovic, D., Machala, L., Zangerle, R., Mocroft, A., Van Lunzen, J., \& EuroSIDA in EuroCoord (2014). Immuno-virological discordance and the risk of non-AIDS and AIDS events in a large observational cohort of HIV-patients in Europe. PloS one, 9(1), e87160. https://doi.org/10.1371/journal.pone.0087160

11. Roan, N. R., \& Jakobsen, M. R. (2016). Friend or Foe: Innate Sensing of HIV in the Female Reproductive Tract. Current HIV/AIDS reports, 13(1), 53-63. https://doi.org/10.1007/s11904-016-0305-0.

12. Mor G. (2013). The female reproductive tract and HIV: biological, social and epidemiological aspects. American journal of reproductive immunology (New York, N.Y. : 1989), 69 Suppl 1, 1. https:/ /doi.org/10.1111/aji.12082

13. Chumachenko, D., \& Chumachenko, T. (2020). Intelligent agent-based simulation of HIV epidemic process doi:10.1007/978-3-030-26474-1_13

14. Kafka, J. K., Sheth, P. M., Nazli, A., Osborne, B. J., Kovacs, C., Kaul, R., \& Kaushic, C. (2012). Endometrial epithelial cell response to semen from HIV-infected men during different stages of infection is distinct and can drive HIV-1-long terminal repeat. AIDS (London, England), 26(1), 27-36. https:// doi.org/10.1097/QAD.0b013e32834e57b2

15. Reekie, J., Kowalska, J. D., Karpov, I., Rockstroh, J., Karlsson, A., Rakhmanova, A., Horban, A., Kirk, O., Lundgren, J. D., Mocroft, A., \& EuroSIDA in EuroCoord (2012). Regional differences in AIDS and non-AIDS related mortality in HIV-positive individuals across Europe and Argentina: the EuroSIDA study. PloS one, 7(7), e41673. https://doi.org/10.1371/journal.pone.0041673

16. Sanderson, P. A., Critchley, H. O., Williams, A. R., Arends, M. J., \& Saunders, P. T. (2017). New concepts for an old problem: the diagnosis of endometrial hyperplasia. Human reproduction update, 23(2), 232-254. https://doi.org/10.1093/humupd/dmw042

17. Mahovlic, V., Ovanin-Rakic, A., Skopljanac-Macina, L., Barisic, A., Rajhvajn, S., Juric, D., Projic, I. S., Ilic-Forko, J., Babic, D., Skrablin-Kucic, S., \& Bozikov, J. (2010). Digital morphometry of cytologic aspirate endometrial samples. Collegium antropologicum, 34(1), 45-51. 
18. Silverberg S. G. (2007). The endometrium. Archives of pathology \& laboratory medicine, 131(3), 372-382. https://doi.org/10.1043/1543-2165(2007)131[372:TE]2.0.CO;2

19. Edi-Osagie, E. C., Seif, M. W., Aplin, J. D., Jones, C. J., Wilson, G., \& Lieberman, B. A. (2004). Characterizing the endometrium in unexplained and tubal factor infertility: a multiparametric investigation. Fertility and sterility, 82(5), 1379-1389. https://doi.org/10.1016/j.fertnstert.2004.04.046

20. Sobczuk, K., \& Sobczuk, A. (2017). New classification system of endometrial hyperplasia WHO 2014 and its clinical implications. Przeglad menopauzalny = Menopause review, 16(3), 107-111. https://doi.org/10.5114/pm.2017.70589

21. Gu, Z., Zhu, P., Luo, H., Zhu, X., Zhang, G., \& Wu, S. (1995). A morphometric study on the endometrial activity of women before and after one year with LNG-IUD in situ. Contraception, 52(1), 57-61. https://doi.org/10.1016/0010-7824(95)00125-t

22. Trimble, C. L., Method, M., Leitao, M., Lu, K., Ioffe, O., Hampton, M., Higgins, R., Zaino, R., Mutter, G. L., \& Society of Gynecologic Oncology Clinical Practice Committee (2012). Management of endometrial precancers. Obstetrics and gynecology, 120(5), 1160-1175. https://doi.org/10.1097/ aog. $0 \mathrm{~b} 013 \mathrm{e} 31826 \mathrm{bb} 121$

23. Henyk, N., Hinchytska, L., Levytskyi, I., Neiko, O., \& Gotsaniuk, R. (2017). The modern approach to the correction of menopausal disorders in women with physiological menopause and after ovariectomy. Galician Medical Journal, 24(2). https://doi.org/10.21802/gmj.2017.2.8

24. Hyriavenko, N., Lyndin, M., Sikora, K., Piddubnyi, A., Karpenko, L., Kravtsova, O., Hyriavenko, D., Diachenko, O., Sikora, V., \& Romaniuk, A. (2019). Serous Adenocarcinoma of Fallopian Tubes: Histological and Immunohistochemical Aspects. Journal of pathology and translational medicine, 53(4), 236-243. https://doi.org/10.4132/jptm.2019.03.21

25. Fernandes, A. T., da Rocha, N. P., Avvad, E., Grinsztejn, B. J., Russomano, F., Tristao, A., Quintana, M., Perez, M. A., Conceicao-Silva, F., \& Bonecini-Almeida, M. (2013). Balance of apoptotic and anti-apoptotic marker and perforin granule release in squamous intraepithelial lesions. HIV infection leads to a decrease in perforin degranulation. Experimental and molecular pathology, 95(2), 166-173. https://doi.org/10.1016/j.yexmp.2013.06.006

26. Litta, P., Agnello, A., \& Azzena, A. (1992). HPV genital infections and contraception. Clinical and experimental obstetrics \& gynecology, 19(2), 136-138.

27. Green A. (2017). The HIV response in Ukraine: at a crossroads. Lancet (London, England), 390(10092), 347-348. https://doi.org/10.1016/S0140-6736(17)31915-3

28. Lu, B., Yu, M., Shi, H., \& Chen, Q. (2019). Atypical polypoid adenomyoma of the uterus: A reappraisal of the clinicopathological and immunohistochemical features. Pathology, research and practice, 215(4), 766-771. https://doi.org/10.1016/j.prp.2019.01.016

29. Zhou, X., Xu, Y., Yin, D., Zhao, F., Hao, Z., Zhong, Y., Zhang, J., Zhang, B., \& Yin, X. (2020). Type 2 diabetes mellitus facilitates endometrial hyperplasia progression by activating the proliferative function of mucin O-glycosylating enzyme GALNT2. Biomedicine $\&$ pharmacotherapy $=$ Biomedecine \& pharmacotherapie, 131, 110764. https://doi.org/10.1016/j.biopha.2020.110764

30. Sivridis, E., \& Giatromanolaki, A. (2011). The pathogenesis of endometrial carcinomas at menopause: facts and figures. Journal of clinical pathology, 64(7), 553-560. https://doi.org/10.1136/ jcp.2010.085951

Received: 19-Oct-2020

Accepted: 13-Dec-2020 